\title{
Genetic differentiation among populations of the Japanese turban shell Turbo (Batillus) cornutus corresponding to warm currents
}

\author{
Shigeaki Kojima ${ }^{1, *}$, Ryoko Segawa $^{2}$, Ikuo Hayashi ${ }^{3}$ \\ ${ }^{1}$ Ocean Research Institute, University of Tokyo, Tokyo 164, Japan \\ ${ }^{2}$ Department of Biology, Faculty oi Science, Tokyo Metropolitan University, Tokyo 192-03, Japan \\ ${ }^{3}$ Japan Sea National Fisheries Research Institute, Niigata 951, Japan
}

\begin{abstract}
The nucleotide sequences of a highly polymorphic region of the mitochondrial gene for cytochrome oxidase I (237 base pair) were determined for 240 individual specimens of the Japanese turban shell Turbo (Batillus) cornutus collected from 12 sites around Japan. Synonymous nucleotide substitutions were detected at 34 positions, and the 49 haplotypes obtained were divided into 2 clusters that formed 'star' phylogenies. The distribution of the 2 clusters was closely related to the pathways of the 2 warm currents along the Japanese Islands, namely, the Kuroshio and Tsushima Currents. The appearance of 2 clusters in the Japan Sea and the Seto Inland Sea is probably attributable to gene flow through the Kanmon Strait during the past 5000 yr. The genetic polymorphism found among the natural populations of the Japanese turban shell provides useful information with which to assess the anticipated genetic disturbance introduced by human activities, such as stocking with artificially bred juvenules.
\end{abstract}

KEY WORDS: Genetic differentiation - Turbo (Batıllus) cornutus - Warm currents - Mitochondrial DNA Japan Sea

\section{INTRODUCTION}

The intraspecific genetic structure of populations of marine animals, as well as those of other organisms, is determined by both historical and contemporary environmental factors (Avise 1994). One of the most important environmental factors in the case of marine animals is the nature of ocean currents. For example, an analysis of restriction fragment length polymorphism (RFLP) of mitochondrial DNA (mtDNA) revealed a dramatic genetic discontinuity in populations of various very different marine animals, such as the horseshoe crab, the American oyster, the diamondback terrapin and the toadfish, between the Gulf of Mexico and the Atlantic coast of the southern United States (Avise 1994). This genetic discontinuity has been attributed to separation during the Pleistocene by a change in sea level and associated aiterations in estuarine habitats.

·E-mail:kojima@ori.u-tokyo.ac.jp
This genetic differentiation between the 2 regions is believed to be maintained by the present pattern of marine currents, namely, the Gulf Stream and the southward nearshore currents along the Atlantic coast, in spite of the continuous distribution of the various species at the present time (Reeb \& Avise 1990).

The direct sequencing of DNA is superior to RFLP analysis as a tool for the accurate estimation of variations in natural populations (Carr \& Marshall 1991). although it requires a greater monetary investment, equipment and materials than RFLP analysis. The recent advances in methods for the direct sequencing of products of PCR (polymerase chain reaction) allow us to obtain DNA sequence data from many individuals at relatively low cost and in a very short time.

The Japanese turban shell Turbo (Batillus) cornutus Lightfoot is a marine prosobranch gastropod that inhabits shallow sublittoral rocky bottoms around the Japanese Islands and South Korea. The geographical distribution of this species is limited to the temperate 


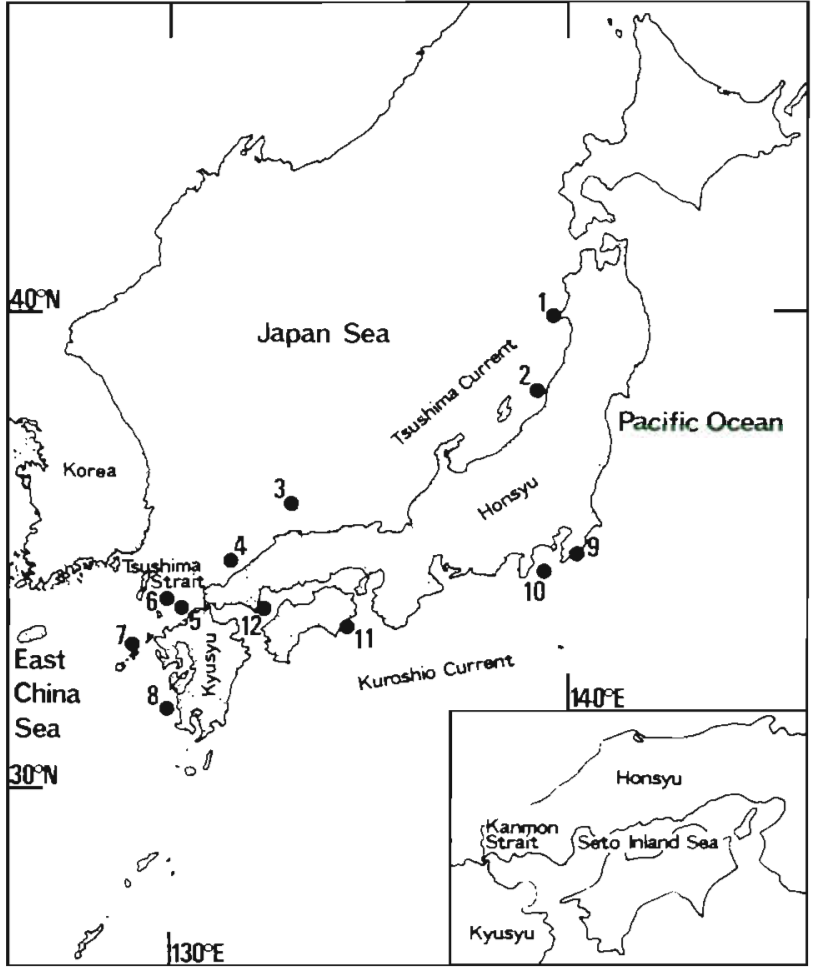

Fig. 1. Distribution of Turbo (Batrllus) cornutus (shaded areas; according to Ozawa \& Tomida 1995) and sites at which Japanese turban shells were collected: 1, Sabashima Island, Akita Prefecture; 2, Awashima Island, Niigata Prefecture; 3. Nishinoshima Island, Shimane Prefecture ${ }_{i} 4$, Mishima lsland, Yamaguchi Prefecture; 5, Ohshima Island, Fukuoka Prefecture; 6, Iki Island, Nagasaki Prefecture; 7, Ojikashima Island, Nagasaki Prefecture; 8, Akune, Kagoshima Prefecture; 9, Uchiura Bay, Chiba Prefecture; 10, Ohshima Island, Tokyo Prefecture; 11 . Ohshima Island, Tokushima Prefecture; 12, Yashirojima Island, Yamaguchi Prefecture. Arrows indicate approximate routes of the Kuroshio and Tsushima Currents (according to Kawai 1972)

coasts that are affected by 2 warm currents, namely the Kuroshio and Tsushima Currents (Fig. 1). The Tsushima Current branches off from the Kuroshio Current south of Kyusyu Island and the currents never meet again (Fig. 1). Larvae of $T$ cornutus are lecithotrophic, with a short planktonic period of 3 to $5 \mathrm{~d}$ (Ai 1965. Toyama 1980) that suggests their limited larval dispersal ability. Thus, we might expect a large genetic difference between populations in the areas along the 2 warm currents.

Turbo cornutus is a commercially important shellfish in Japan, and the artificial enhancement of its production by the stocking of open-sea areas with a large number of artificially bred juveniles has become of increasing interest (Okabe et al. 1989). In the near future, the genetic structures of populations of $T$ cornutus may well be affected by such human activities. The present study was designed to clarify the genetic structure of these populations under 'natural conditions' by an analysis of the nucleotide sequence of part of a mitochondrial gene from Japanese turban. shells collected at various sites around Japan. The results provide basic information for future assessment of the effects of human activities on these populations.

\section{MATERIALS AND METHODS}

In all, 240 individual specimens of Turbo cornutus were collected from 12 sites (Fig. 1), which covered its geographical distribution around the Japanese Islands. Most of the sampling sites were chosen close to remote islands where we judged that disturbance by human activities would be less frequent and where native populations would be well preserved. Samples were dissected and kept in a deep-freezer $\left(-80^{\circ} \mathrm{C}\right)$. mtDNA was extracted from the liver of each specimen by a modified version of the method of Komm et al. (1982).

Using PCR, we amplified part of the gene for cytochrome oxidase I (COI), which had been shown to contain sufficient variations in nucleotide sequence for the analysis of population structure in a comparison of almost the entire nucleotide sequence of the gene for COI among individuals collected from Awashima, Niigata Prefecture, and from Ohshima, Tokyo Prefecture (authors' unpubl. data). The primers employed were COI-3, 5'-GTNTGRGCNCAYCAYATRTTYACNGT-3', corresponding to amino acid residues 285293 encoded by the gene from Drosophila yakuba for COI, and COI-6, 5'-GGRTARTCNSWRTANCGNCGNGGYAT-3', corresponding to residues $434-442$ encoded by the gene from $D$. yakuba. These primers are 'universal' primers for most metazoan genes for $\mathrm{COI}$ (Shimayama et al. 1990). The conditions for PCR were as follows: $94^{\circ} \mathrm{C}$ for $60 \mathrm{~s}$; then 30 to 40 cycles at $92^{\circ} \mathrm{C}$ for $40 \mathrm{~s}, 40^{\circ} \mathrm{C}$ for $60 \mathrm{~s}$, and $72^{\circ} \mathrm{C}$ for $90 \mathrm{~s}$. Gene Releaser ${ }^{\mathrm{TM}}$ (BioVenture Inc., Murfreesboro, TN, USA) was used to sequester products of cell lysis that might have inhibited the polymerase.

Nucleotide sequences of $237 \mathrm{bp}$, which contained sufficient variability as indicated above, were determined by the dideoxynucleotide chain-termination method with a Sequenase ${ }^{T H}$ PCR product sequencing kit (United States Biochemical Corp.) using primers COI-3 and COI-6. Amino acid sequences of COI were deduced by reference to the modified genetic code of molluscan mtDNA (Shimayama et al. 1990, Hoffmann et al. 1992).

Differences in the frequencies of haplotypes between populations were tested by a randomized chisquared test of independence (Roff \& Bentzen 1989). Chi-squared values were generated from 1000 simulated random samplings of the data. 


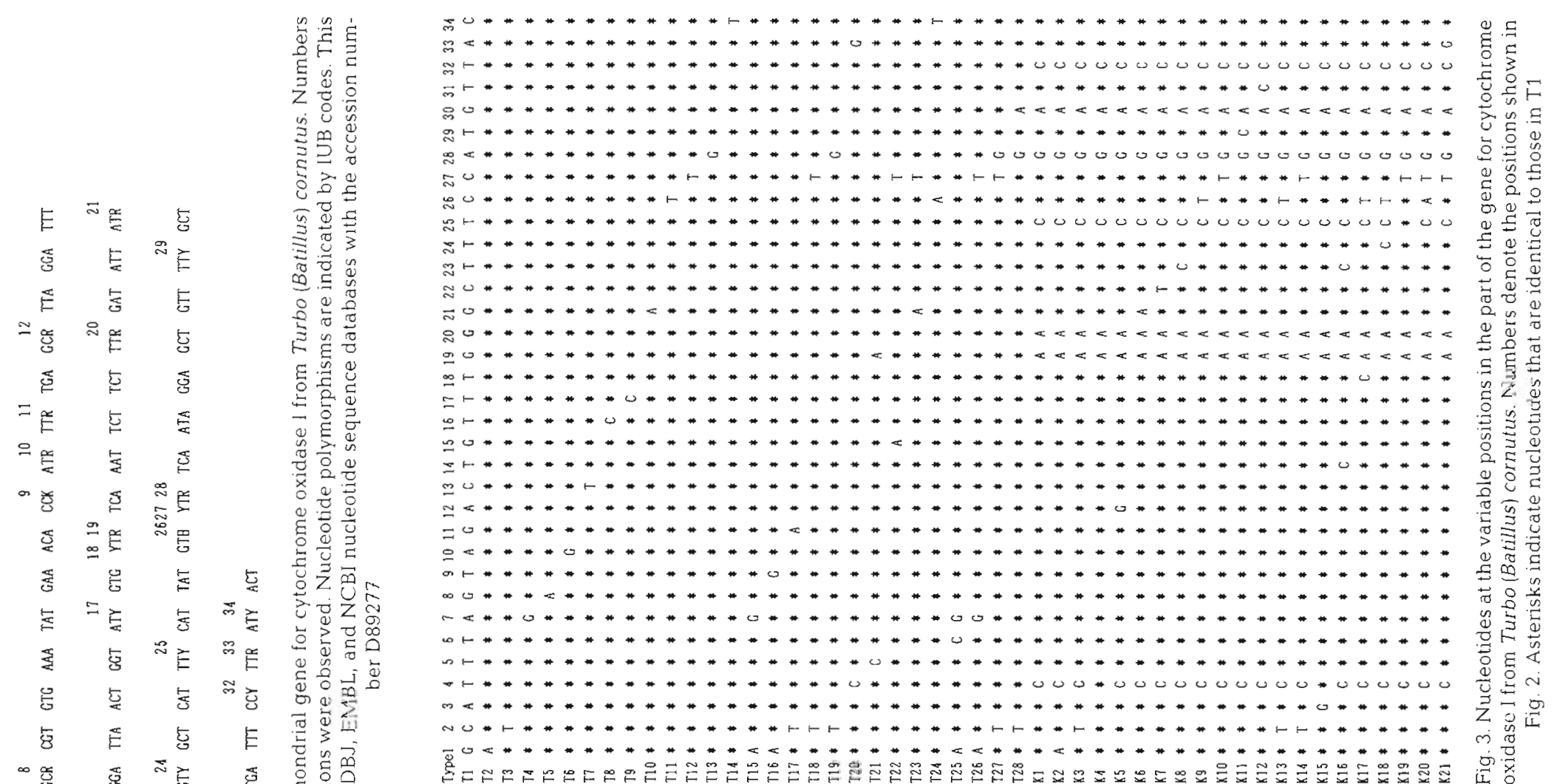

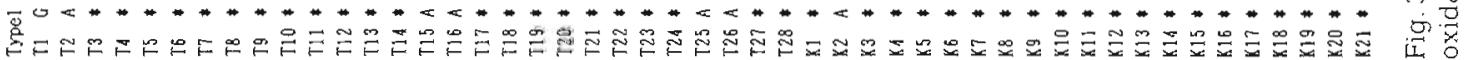

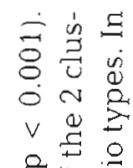

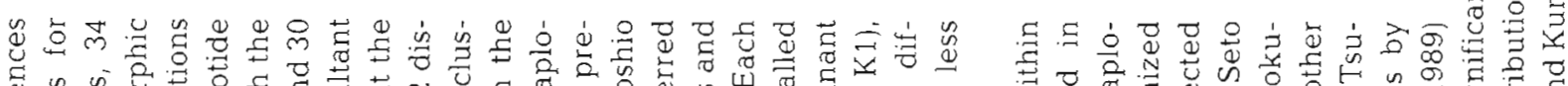

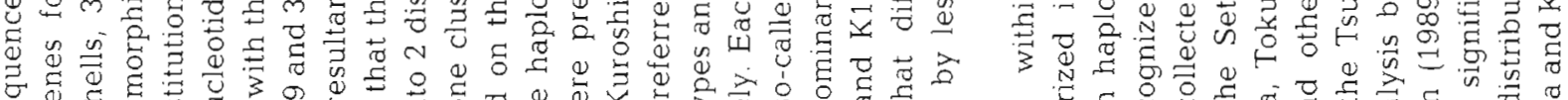

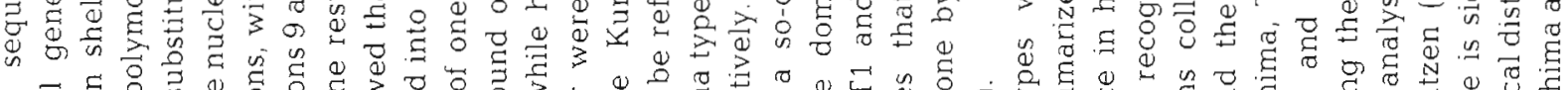

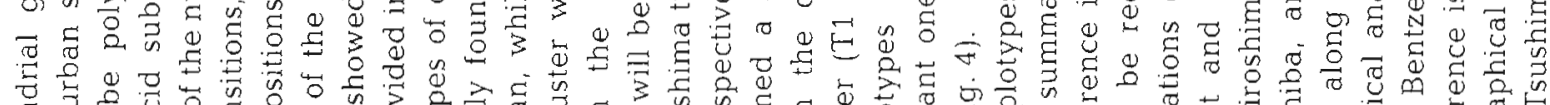

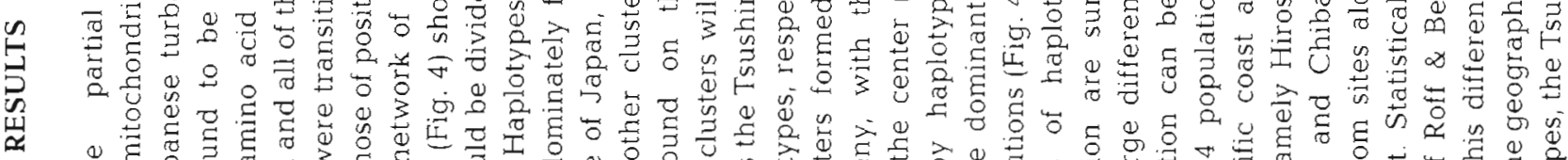

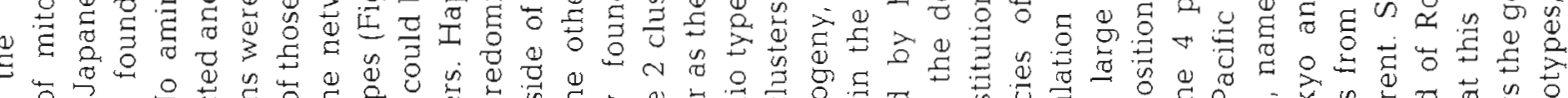

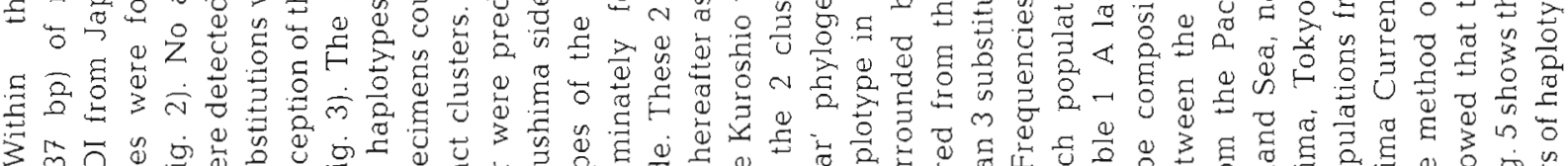

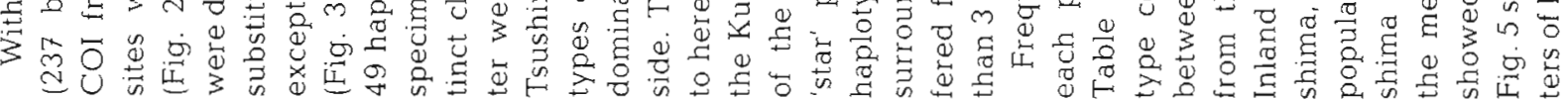




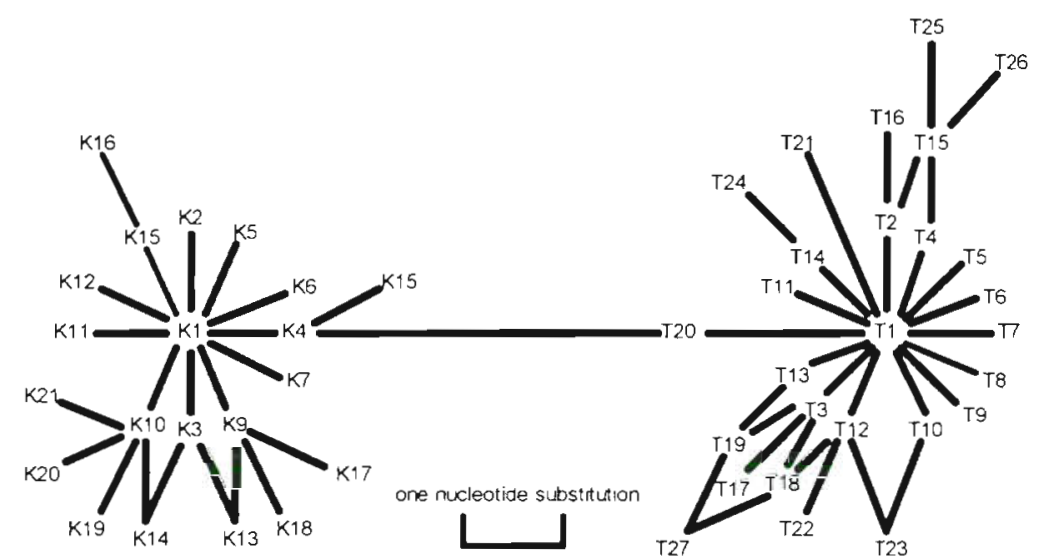

Fig. 4. Network of haplotypes. Lengths of lines between haplotypes denote the numbers of nucleotide substitutions between them

Kuroshio types was slightly higher than at the north Kyusyu sites. By contrast, haplotypes of individuals collected in the Seto Inland Sea (Site 12) were mainly of the Kuroshio types and only 2 of $20 \mathrm{spec}$ imens were the Tsushima types.

\section{DISCUSSION}

The present analysis, based on the nucleotide sequences of a portion of the mtDNA, clearly revealed the genetic structure of populations of Japanese turban shells. The 240 specimens that we analyzed could be divided into 2 distinct haplotype clusters, the Tsushima types

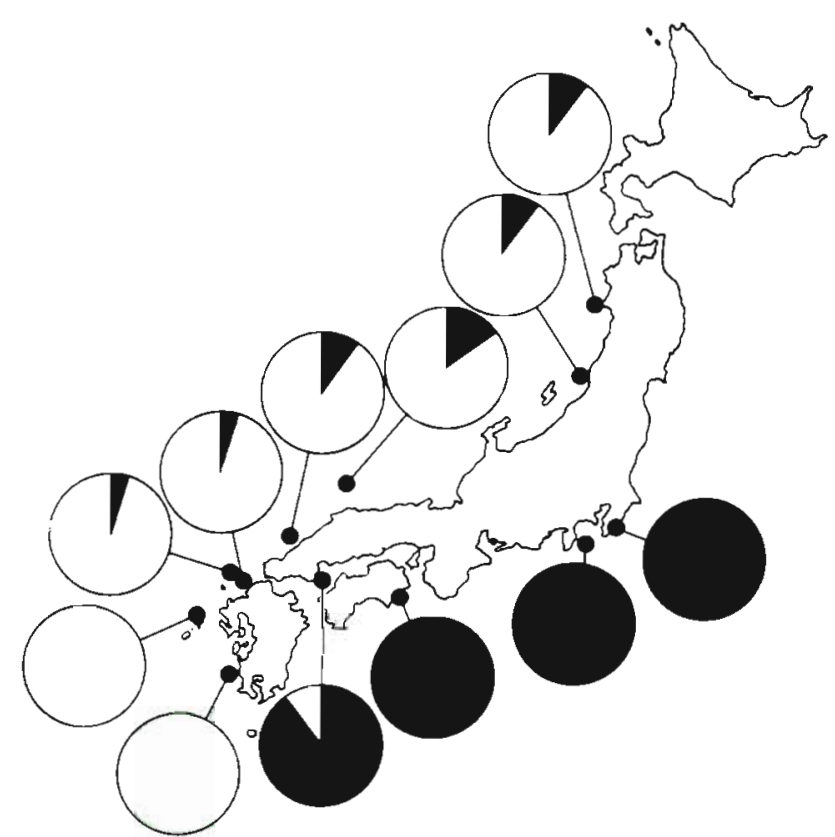

Fig. 5. Geographical distribution of the 2 groups of haplotypes, the Kuroshio and Tsushima types. Black and white areas in the circles indicate the relative frequencies of the Kuroshio and Tsushima types, respectively

sitions of populations from sites along the Tsushima Current were more complicated. All individuals from populations at 2 sites (Sites 7 and 8 in Fig. 1) in the upstream region of the current. west of Kyusyu Island facing the East China Sea, had mtDNA of the Tsushima types. In the middle region of the Tsushima Current, north of Kyusyu Island, the populations sampled at 2 sites (Sites 5 and 6 ) included a few individuals with Kuroshio-type sequences. In the populations from the 4 sites along the Japan Sea coast of Honsyu Island (Sites 1 to 4 ), the frequency of haplotypes of the and the Kuroshio types, and the proportions of these types varied among regional populations. The phylogeographical characteristics of the Japanese turban shell resemble those of the European anchovy (Magoulas et al. 1996). RFLP analysis of mtDNA of European anchovies collected from the Black Sea, the Mediterranean and the Atlantic showed that their haplotypes could be divided into 2 distinct clusters which represented different geographical distributions. Magoulas et al. (1996) attributed this heterogeneous phylogeographical structure to the isolation of the Black Sea from the Mediterranean during the glacial periods and the subsequent post-glacial, one-way dispersal from the Black Sea to the Mediterranean.

In the case of the Japanese turban shell, the pathways of the 2 warm currents, the Kuroshio and Tsushima Currents, appear to explain the trends in the genetic structures of populations identified in this study. The Tsushima Current branches off from the Kuroshio Current and they never join each other again. The distribution of the 2 haplotype clusters corresponds closely to the paths of the 2 warm currents. The 2 clusters probably evolved during the periods when they were isolated from each other, and the present coexistence observed at some sites might be the result of secondary contacts (Avise et al. 1987 , Magoulas et al. 1996). Each cluster formed a 'star' phylogeny that consisted of one dominant haplotype and some rarer haplotypes, with the latter differing from the dominant haplotype by less than 3 nucleotide substitutions. Since haplotypes $\mathrm{K} 1$ and T1 were detected at high frequency and were located in the center of the 'star' phylogenies, these are likely to be the ancestral forms in each cluster. The 'star' phylogeny suggests a dramatic bottleneck that was followed by an explosion in population size (Magoulas et al. 1996). The phylogenetic network also suggests that population bottlenecks occurred not only on the 
Table 1 Haplotype composition of each population of Turbo (Batillus) cornutus collected from 12 sites around Japan. Sampling sites are those shown in Fig. 1

\begin{tabular}{|c|c|c|c|c|c|c|c|c|c|c|c|c|c|}
\hline \multirow[t]{2}{*}{ Type } & \multicolumn{13}{|c|}{ Sampling site } \\
\hline & 1 & 2 & 3 & 4 & 5 & 6 & 7 & 8 & 9 & 10 & 11 & 12 & Tot. \\
\hline T1 & 10 & 8 & 5 & 5 & 6 & 6 & 12 & 6 & 0 & 0 & 0 & 1 & 59 \\
\hline T2 & 1 & 2 & 1 & 3 & 7 & 5 & 2 & 4 & 0 & 0 & 0 & 1 & 26 \\
\hline T3 & 1 & 0 & 0 & 0 & 0 & 0 & 0 & 0 & 0 & 0 & 0 & 0 & 1 \\
\hline$T_{4}$ & 0 & 0 & 0 & 0 & 0 & 0 & 0 & 1 & 0 & 0 & 0 & 0 & 1 \\
\hline T5 & 0 & 0 & 1 & 0 & 0 & 0 & 0 & 0 & 0 & 0 & 0 & 0 & 1 \\
\hline T6 & 0 & 0 & 0 & 0 & 0 & 1 & 0 & 0 & 0 & 0 & 0 & 0 & 1 \\
\hline $\mathrm{T} 7$ & 0 & 1 & 1 & 0 & 0 & 1 & 0 & 0 & 0 & 0 & 0 & 0 & 3 \\
\hline T8 & 0 & 0 & 0 & 0 & 0 & 0 & 1 & 0 & 0 & 0 & 0 & 0 & 1 \\
\hline T9 & 0 & 0 & 1 & 0 & 0 & 0 & 0 & 0 & 0 & 0 & 0 & 0 & 1 \\
\hline T10 & 0 & 0 & 0 & 1 & 0 & 0 & 0 & 0 & 0 & 0 & 0 & 0 & 1 \\
\hline T11 & 0 & 1 & 1 & 2 & 0 & 1 & 0 & 1 & 0 & 0 & 0 & 0 & 6 \\
\hline T12 & 2 & 0 & 0 & 1 & 2 & 1 & 0 & 1 & 0 & 0 & 0 & 0 & 7 \\
\hline T13 & 0 & 3 & 0 & 2 & 0 & 0 & 2 & 0 & 0 & 0 & 0 & 0 & 7 \\
\hline T14 & 1 & 1 & 3 & 1 & 1 & 2 & 2 & 1 & 0 & 0 & 0 & 0 & 12 \\
\hline T15 & 0 & 1 & 0 & 0 & 1 & 1 & 1 & 1 & 0 & 0 & 0 & 0 & 5 \\
\hline T16 & 0 & 0 & 0 & 0 & 0 & 0 & 0 & 1 & 0 & 0 & 0 & 0 & 1 \\
\hline T17 & 2 & 0 & 0 & 0 & 0 & 0 & 0 & 2 & 0 & 0 & 0 & 0 & 4 \\
\hline T18 & 0 & 0 & 0 & 0 & 1 & 0 & 0 & 0 & 0 & 0 & 0 & 0 & 1 \\
\hline T19 & 0 & 0 & 0 & 0 & 0 & 1 & 0 & 1 & 0 & 0 & 0 & 0 & 2 \\
\hline T20 & 0 & 0 & 1 & 0 & 0 & 0 & 0 & 0 & 0 & 0 & 0 & 0 & 1 \\
\hline $\mathrm{T} 21$ & 0 & 0 & 1 & 0 & 0 & 0 & 0 & 0 & 0 & 0 & 0 & 0 & 1 \\
\hline $\mathrm{T} 22$ & 0 & 0 & 1 & 0 & 0 & 0 & 0 & 0 & 0 & 0 & 0 & 0 & 1 \\
\hline $\mathrm{T} 23$ & 0 & 0 & 0 & 1 & 0 & 0 & 0 & 0 & 0 & 0 & 0 & 0 & 1 \\
\hline T24 & 0 & 1 & 0 & 0 & 0 & 0 & 0 & 0 & 0 & 0 & 0 & 0 & 1 \\
\hline $\mathrm{T} 25$ & 0 & 0 & 1 & 1 & 0 & 0 & 0 & 1 & 0 & 0 & 0 & 0 & 3 \\
\hline T26 & 0 & 0 & 0 & 1 & 0 & 0 & 0 & 0 & 0 & 0 & 0 & 0 & 1 \\
\hline T27 & 1 & 0 & 0 & 0 & 0 & 0 & 0 & 0 & 0 & 0 & 0 & 0 & 1 \\
\hline $\mathrm{T} 28$ & 0 & 0 & 0 & 0 & 1 & 0 & 0 & 0 & 0 & 0 & 0 & 0 & 1 \\
\hline $\mathrm{K} 1$ & 2 & 2 & 0 & 2 & 1 & 0 & 0 & 0 & 8 & 8 & 11 & 7 & 41 \\
\hline $\mathrm{K} 2$ & 0 & 0 & 0 & 0 & $\hat{0}$ & 0 & 0 & 0 & 0 & 2 & 0 & 0 & 2 \\
\hline $\mathrm{K} 3$ & 0 & 0 & 0 & 0 & 0 & 0 & 0 & 0 & 0 & 0 & 3 & 0 & 3 \\
\hline K4 & 0 & 0 & 1 & 0 & 0 & 0 & 0 & 0 & 0 & 1 & 0 & 0 & 2 \\
\hline K5 & 0 & 0 & 0 & 0 & 0 & 0 & 0 & 0 & 0 & 0 & 0 & 1 & 1 \\
\hline K6 & 0 & 0 & 0 & 0 & 0 & 0 & 0 & 0 & 1 & 0 & 0 & 0 & 1 \\
\hline K7 & 0 & 0 & 0 & 0 & 0 & 0 & 0 & 0 & 0 & 0 & 1 & 0 & 1 \\
\hline K8 & 0 & 0 & 0 & 0 & 0 & 0 & 0 & 0 & 2 & 1 & 0 & 1 & 4 \\
\hline K9 & 0 & 0 & 1 & 0 & 0 & 0 & 0 & 0 & 5 & 2 & 2 & 4 & 14 \\
\hline K10 & 0 & 0 & 0 & 0 & 0 & 0 & 0 & 0 & 1 & 0 & 0 & 1 & 2 \\
\hline $\mathrm{K} 11$ & 0 & 0 & 0 & 0 & 0 & 0 & 0 & 0 & 0 & 1 & 0 & 0 & 1 \\
\hline $\mathrm{K} 12$ & 0 & 0 & 0 & 0 & 0 & 1 & 0 & 0 & 0 & 2 & 1 & 1 & 5 \\
\hline $\mathrm{K} 13$ & 0 & 0 & 1 & 0 & 0 & 0 & 0 & 0 & 0 & 0 & 0 & 0 & 1 \\
\hline $\mathrm{K} 14$ & 0 & 0 & 0 & 0 & 0 & 0 & 0 & 0 & 0 & 0 & 0 & 1. & 1 \\
\hline K15 & 0 & 0 & 0 & 0 & 0 & 0 & 0 & 0 & 1 & 1 & 0 & 0 & 2 \\
\hline $\mathrm{K} 16$ & 0 & 0 & 0 & 0 & 0 & 0 & 0 & 0 & 0 & 1 & 0 & 0 & 1 \\
\hline $\mathrm{K} 17$ & 0 & 0 & 0 & 0 & 0 & 0 & 0 & 0 & 1 & 0 & 0 & 0 & 1 \\
\hline K18 & 0 & 0 & 0 & 0 & 0 & 0 & 0 & 0 & 0 & 0 & 2 & 1 & 3 \\
\hline K19 & 0 & 0 & 0 & 0 & 0 & 0 & 0 & 0 & 0 & 1 & 0 & 0 & 1 \\
\hline $\mathrm{K} 20$ & 0 & 0 & 0 & 0 & 0 & 0 & 0 & 0 & 1 & 0 & 0 & 0 & 1 \\
\hline $\mathrm{K} 21$ & 0 & 0 & 0 & 0 & 0 & 0 & 0 & 0 & 0 & 0 & 0 & 1 & 1 \\
\hline Tot. & & 20 & 20 & 20 & 20 & 20 & 20 & 20 & 20 & 20 & 20 & 20 & 240 \\
\hline
\end{tabular}

coast along the Tsushima Current but also along the Pacific coast.

The rate of substitutions between the 2 ancestral haplotypes, as calculated by Kimura's 2-parameter method (Kimura 1980), was 0.031. If the rate of evolu- tion of COI of the darking beetle, namely 0.02 substitutions per million yr (Juan et al. 1995) is used, the divergence between the 2 clusters can be estimated to have occurred 1.6 million yr ago (Ma). This value is probably an overestimate because only the highly polymorphic region of the COI gene of the Japanese turban shell was used. Chinzei (1991) suggested that a system of warm currents similar to the present one along the Japan Islands had already been established 17 to $15 \mathrm{Ma}$, before the spread of the Japan Sea. Fossils of the genus Turbo have been reported from the coast of the Japan Sea in the deposition of this age (Kobayashi \& Horikoshi 1958). After the spread of the Japan Sea, the first appearance of warm-water benthic molluscs was reported to be have occurred 1.3 Ma and, thereafter, the cold-and warm-water fauna in the Japan Sea were estimated to alternate with glacio-eustatic changes in sea-level during the last 1.3 million $y r$ (Kanazawa 1990, Kitamura \& Kondo 1990). During the course of a series of reductions in suitable habitats for the Japanese turban shell in the glacial periods, the genetic differentiation that we have detected may have occurred and then been maintained until the present time.

During glacial periods, it is assumed that warm currents did not flow into the Japan Sea (Ujiie et al. 1991, Ahagon et al. 1993) and it might have led to cold surface-water conditions in the Japan Sea, as clearly indicated by the species composition of planktonic foraminiferans and diatoms in the Japan Sea at that time (Tanimura 1981, Oba 1991, Oba et al. 1991). The taxonomical and geochemical analysis of microfossil assemblages in piston core samples (Tanimura 1981, Oba 1988, 1991, Oba et al. 1991) also revealed the severe anoxic conditions caused by the input of a significant amount of fresh water into the surface layer and the subsequent stratification of the water column in the Japan Sea during the middle period of the last glacial period (27000 to $20000 \mathrm{yr}$ ago). Oba et al. (1991) suggested that most of the benthic fauna was probably eliminated during this period. The temperature of the sea surface in the Japan Sea at the end of the last glacial period ( 20000 to $10000 \mathrm{yr}$ ago) was estimated to be low, as a result of the inflow of the Oyashio cold current, from micropaleontological evidence (Oba et al. 1991). During this period, the environment of the Japan Sea was unsuitable for species that originated in tropical areas, such as turban shells. The analysis of oxygen isotopes in tests of both planktonic and benthic foraminiferans in a piston core sample taken off the western coast of Kyusyu Island showed that the Tsushima Current has flowed over this area for the last 30000 yr (Oba 1991). Therefore, the main habitat of the Japanese turban shell with the Tsushima type of mtDNA was probably restricted to the western coast of 
Kyusyu Island, which is likely to have become a refuge during the glacial periods.

Micropaleontological evidence (Oba 1991, Oba et al. 1991) indicates that the continuous inflow of the warm Tsushima Current into the Japan Sea began 8000 yr ago, when the present oceanographic conditions of the Japan Sea were established. Then Japanese turban shells, which had survived in a refuge outside the Japan Sea, might have entered through the Tsushima Strait and colonized the Japan Sea. The colonized populations probably consisted of individuals with the Tsushima type of mtDNA, just like the present populations off the western coast of Kyusyu Island. After the 2 types of population became established, respectively, in the Japan Sea and on the Pacific coasts, the Kanmon Strait, a narrow (about $500 \mathrm{~m}$ ) strait of $12 \mathrm{~m}$ in depth that is located between Kyusyu and Honsyu Islands, was formed 5000 yr ago (Ohshima 1990). The mixture of a few individuals with the Kuroshio type of mtDNA in the Japan Sea and those with the Tsushima type in the Seto Inland Sea is probably the result of the gene flow through the Kanmon Strait during the last 5000 yr.

The present study revealed the large genetic diversity in the populations of Japanese turban shells around Japan. Although the genetic polymorphism revealed in the present study is probably selectively neutral, genetically distinct populations of Japanese turban shells might have their own genes that are adaptive to their native habitats. The artificial transplantation of individuals from allopatric populations might result in the loss of such a genetic advantage from the regional populations. In addition, the genetic diversity of reared juveniles is usually much lower than that of a natural population because the former are produced from only a few parental lines. Thus, the stocking of reared individuals should be carried out with careful planning and detailed monitoring of possible genetic perturbations. The genetic polymorphism revealed in this study provides useful tools not only for evaluation of the productive success of stocks but also for assessment of the degree of genetic disturbance caused by human activities.

Acknowledgements. For collection of samples, the authors thank the staff of Akita Prefectural Fisheries Promotion Center, Shimane Prefectural Fisheries Experimental Station, Yamaguchi Prefectural Galkai Fisheries Experimental Station, Fukuoka Fisheries and Marine Technology Research Center, Nagasaki Prefectural Institution of Fisheries, Fisheries Research Station of Kagoshima Prefecture, Tokyo Metropolitan Sea-Farming Center, Fisheries Division of Tokushima Prefectural Government. Nansei National Fisheries Research Institute and the Komınato Marine Laboratory, Marine Ecosystems Research Center, Chiba University.

\section{LITERATURE CITED}

Ahagon N, Tanaka Y, Ujie H (1993) Florsphaera profunda, a possible nannoplankton indicator of late Quatemary changes in sea-water turbidity at the northwestern margin of the Pacific. Mar Micropaleontol 22:255-273

Al T (1965) Spawning and early development of the topshell, Turbo cornutus Solander-II. Induction of spawning and larval development. Bull Jpn Soc Sci Fish 31:105-112 (in Japanese with English abstract.)

Avise JC (1994) Molecular markers, natural history and evolution. Chapman \& Hall, New York

Avise JC, Arnold J, Ball RM, Bermingham E, Lamb T, Niegel JE, Reeb CA, Saunders NC (1987) Intraspecific phylogeography: the mitochondrial DNA bridge between population genetics and systematics. Annu Rev Ecol Syst 18 $489-522$

Carr SM, Marshall HD (1991) A direct approach to the measurement of genetic variation in fish populations: applications of the polymerase chain reaction to studies of Atlantic cod, Gadus morhua L. J Fish Biol 39(Suppl A) $101-107$

Chinzei K (1991) Late Cenozoic zoogeography of the Sea of Japan area. Episodes 14:231-235

Hoffmann RJ, Boore JL, Brown WM (1992) A novel mitochondrial genome organization for the blue mussel, Mytilus edulis. Genetics 131:397-412

Juan C. Oromi P. Hewitt GM (1995) Mitochondrial DNA phy. logeny and sequential colonization of Canary Islands by darking beetles of the genus Pimelia (Tenebrionidae) Proc R Soc Lond Ser B Biol Sci 261:173-180

Kanazawa K (1990) Early Pleistone glacio-eustatic sea-level fluctuations as deduced from periodic changes in coldand warm-water molluscan assocıations in the Shimokita Peninsula, Northeast Japan. Palaeogeogr Palaeoclimatol Palaeoecol 79:263-273

Kawai $H$ (1972) Hydrography of the Kuroshio extension. In: Stommel H. Yoshida K leds) Kuroshio-its physıcal aspects. Tokyo Univ Press, Tokyo, p $23 j 332$

Kimura M (1980) A simple method for estimating evolutionary rate of base substitutions through comparative studies of nucleotide sequence. J Mol Evol 16:111-120

Kitamura A, Kondo Y (1990) Cyclic changes of sedments and molluscan fossil associations caused by glacio-eustatic sea-level changes during the early Pleistocene-a case study of the middle part of the Omma Formation at the type locality. J Geol Soc Jpn 96:19-36 (in Japanese with English abstract)

Kobayashi T, Horikoshi M (1958) Indigenous Aturia and some tropical gastropods from the Miocene of Wakasa in West Japan. Jpn J Geol Geogr 29:45-54

Komm B, Michaels A, Linton J (1982) Isolation and characterization of the mitochondrial DNA from the Florida spiny lobster, Panulirus argus. Comp Biochem Physiol 73B: 923-929

Magoulas A. Tsimenides N, Zouros E (1996) Mitochondrial DNA phylogeny and the reconstruction of the population history of a species: the case of the European anchovy (Engraulis encrasicolus). Mol Biol Evol 13:178-190

Oba T (1988) Comment for sea level change. Quat Res Tokyo 26:243-250 (in Japanese with English abstract)

Oba T (1991) Oceanic paleoenvironmantal studies in Japan. Quat Res Tokyo 30:197-202

Oba T, Kato M, Kitazato H, Koizumi I, Omura A, Sakai T, Takayama $T$ (1991) Paleoenvironmental changes in the Japan Sea during the last 85,000 years. Paleoceanography $6: 499-518$ 
Ohshima K (1990) The history of straits around Japanese Islands in the Late-Quaternary. Quat Res Tokyo 29: 193-208 (in Japanese with English abstract)

Okabe M, Kuwahara A, Nishimura M, Yoshida M (1989) Marine ranching of the topshell, Batillus cornutus. Japan Fisheries Resource Conservation Association, Tokyo (in Japanese with English abstract)

Ozawa T, Tomida S (1995) A new Turbo (Batillus) species from (hinese coasts. Venus (Jpn J Malacol) 54:269-277

Reeb C. A, Avise JC (1990) A genetic discontınuity in a continuously distributed species: mitochondrial DNA in the American oyster, Crassostrea virginuca. Genetics 124:397-406

Roff DA, Bentzen P (1989) The statistical analysis of mito-

This article was submitted to the editor chondrial DNA polymorphisms and the problem of small samples. Mol Biol Evol 6:539-545

Shımayama T, Himeno H, Sasuga J, Yokobori S, Ueda $T$, Watanabe K (1990) The grenetic code of a squid mitochondrial gene. Nucleic Acids Symp Ser 22:77-78

Tanimura Y (1981) Late Quaternary diatoms and palaeoceanography of the Sea of Japan. Quat Res Tokyo 20: 231-242 (in Japanese with English abstract)

Toyama T (1980) Studies on the seed production of Turbo cornutus. Ocean Age 12:59-66 (in Japanese)

Ujiie H, Tanaka Y, Ono T (1991) Late Quarternary paleoceanographic record from the middle Ryukyu Trench slope, northwest Pacific. Mar Micropaleontol 18:115-128

Manuscript first received: November 26, 1996

Revised version accepted: February 25, 1997 